\title{
Por uma leitura historiográfica da dispersão urbana
}

\author{
For a historical interpretation of urban sprawl \\ Para una lectura historiográfica de la expansión urbana
}

\author{
(1) Carolina Pescatori \\ Universidade de Brasília, PPG/FAU, Brasília, Brasil. pescatori@unb.br

\section{(1D) Rodrigo de Faria} \\ Universidade de Brasília, PPG/FAU, Brasília, Brasil. rod.dfaria@gmail.com
}

\section{Resumo}

Parte das teorias contemporâneas sobre a forma da cidade foca-se em um debate dual: de um lado, estudos demonstram a intensidade do crescimento e a expansão da urbanização, formando uma leitura de cidade dispersa, considerada, por alguns autores, como a morte da cidade; de outro, investigações objetivam frear essa dispersão e prover respostas urbanísticas baseadas no resgate da cidade "tradicional", formando uma leitura de cidade compacta. O embate entre essas leituras é central para a discussão acerca da urbanização contemporânea, que ainda carece de leituras que considerem a dispersão urbana dentro de uma perspectiva historiográfica.

Palavras-chave: história do urbanismo, cidade compacta; cidade dispersa.

\section{Abstract}

Part of the contemporary urban morphology theories focuses on a dual debate: on one hand, studies have shown the strong growth and expansion of urbanization, forming the interpretation of the dispersed city, 
considered by some authors as the death of the city; on the other, studies aim to curb sprawl, and provide answers based on the rescue of the "traditional" city, forming the interpretation of the compact city. The conflict between these interpretations is central to the contemporary urbanization debate, which lack interpretations that take into account the historiography perspective.

Keywords: history of urbanism, dispersed city, urban sprawl, compact city. 


\section{INTRODUÇÃO}

O objetivo deste artigo é aprofundar o debate sobre a cidade compacta como "solução" para a cidade dispersa. Grande parte da literatura contemporânea sobre planejamento e projeto urbanístico apresenta uma leitura que, majoritariamente, caracteriza a dispersão urbana como uma ruptura no processo histórico de urbanização, entendendo-a como um fenômeno completamente novo. Somam-se a essa interpretação leituras que compreendem a dispersão como um fenômeno problemático, que implica degradação da cidade e de suas configurações tradicionais, deformadas nas/pelas expressões espaciais da cidade dispersa. No embasamento dessas interpretações, persiste a abordagem hegemônica de que a compactação urbana, materializada em leituras de cidade compacta, representa a solução urbanística ideal, transposta tanto para o desenho da cidade quanto para os instrumentos e diretrizes de planejamento territorial.

Neste trabalho, procuramos problematizar criticamente essas visões dominantes sobre a cidade contemporânea, com vistas a reconhecer a cidade dispersa como parte legítima da cidade, a partir de uma interpretação teórica e historiográfica do pensamento urbanístico. $\mathrm{O}$ artigo apresenta uma discussão teórica em duas frentes argumentativas. Na primeira, debatemos com autores que afirmam que a dispersão urbana e suas formas representam a morte da cidade, ou mesmo a anticidade. Na contramão dessa a ideia, salientamos que a dispersão, por mais desconcertante e transformadora que seja, não significa o fim da cidade, mas que é apenas uma de suas (várias) transformações históricas.

Na segunda frente de argumentação, afirmamos que a dispersão urbana não é um fenômeno completamente novo ou desconectado de antecedentes no pensamento e na prática urbanística, enquanto buscamos reconhecer a dispersão como fenômeno intrínseco à urbanização contemporânea, construído historicamente tanto no debate urbanístico, quanto no espaço físico da cidade.

\section{Compactação e dispersão: um embate de ideias no campo do urbanismo e o falso fim da cidade}

O fenômeno da urbanização dispersa não se restringe ao contexto brasileiro, ou latino-americano, mas configura-se como realidade global, transnacional caracte- 
rizada por dois pontos centrais: a expansão rápida e ampla das áreas urbanizadas; a dispersão dos tecidos urbanos. Segundo Nestor Goulart, a urbanização dispersa é "(...) a extensão dos tecidos urbanos por vastos territórios, separados no espaço, mas mantendo estreitos vínculos entre si, como partes de um único sistema urbano" (REIS FILHO, 2006, p. 12).

Para o autor, esta extensão pode se dar de diversas formas, como por meio de grupos de cidades médias e pequenas que estabelecem fortes relações cotidianas, organizando-se de modo integrado; por meio da criação de novos polos de atração, separados dos núcleos existentes nas proximidades (como é o caso de Alphaville-Barueri, verdadeira cidade-paralela dentro dos municípios de Santana do Parnaíba e Barueri, na Região Metropolitana de São Paulo); e mesmo por novos polos suburbanos, "megaempreendimentos fechados", ou "áreas autônomas de reurbanização, em meio ao tecido tradicional" (REIS FILHO, 2006, p. 47). A dispersão urbana trata, enfim, das formas de expansão da cidade que ocorreram a partir da segunda metade do século $X X$, tendo sido bastante estudada no exterior e no Brasil, e sendo reconhecida por muitos pesquisadores como irreversível, global, mas também como problemática, ambientalmente dispendiosa, socialmente excludente, culturalmente empobrecida, resultado de um modelo de urbanização privada que visa à ampliação de lucros particulares e a especulação imobiliária1.

São muitos os conceitos que permeiam as interpretações sobre a urbanização dispersa no final do século XX. Segundo Bernardo Secchi, teóricos e pesquisadores da cidade criaram uma espécie de "bulimia terminológica" para definir os processos de urbanização, incluindo a megalópole, o sprawl do subúrbio americano, a cidade difusa, a edgecity, as regional cities, e as sprawlcities como descrições da mesma forma de urbanização dispersa. Para o autor, estes conceitos diversos apenas descrevem diferentes nuances de um mesmo fenômeno, sendo esta diversidade "indicadora do embaraço que as novas formas de urbanização suscitam em seus observadores" (SECCHI, 2009, pp. 44-45)

A característica mais marcante da urbanização dispersa é a extensão da malha urbana e do modo de produção urbano para além dos limites da cidade consolidada, conforme afirma Monte-Mór (2007). Esta expansão se dá com o predomínio das baixas densidades habitacionais apoiadas em amplo sistema de infraestrutura viária, como destacam Monclús (1998), Dematteis (1998), Reis (2006), Spósito (2007), e Catalão (2009). No entanto, este crescimento territorial da cidade do século XXI não está mais ligado à migração campo-cidade, como no século XX; agora a expansão territorial se dá pela acomodação de uma população já urbana, que tem o modo de vida urbano completamente assimilado.

1 Dentre estes autores, destacamos os trabalhos de Javier Monclús e Zaida Muxína Espanha; Francesco Indovina e Bernardo Secchi, na Itália; Nuno Portas e Álvaro Domingues, em Portugal; Edward Soja, Robert Fishman, Dolores Haydennos EUA; e no Brasil, Nestor Goulart Reis; Roberto Monte-Mór; e Maria Encarnação Spósito. 
Outro aspecto significativo da dispersão urbana é a fragmentação da ocupação do território que deixa extensos espaços menos adensados entre núcleos ocupados, espaços estes que são muitas vezes erroneamente interpretados como "vazios", mas que constituem partes produtivas e intrínsecas à cidade e as suas dinâmicas. Segundo Milton Santos, esta configuração mais complexa e imbricada entre urbano e rural está ligada ao processo de informacionalização do território, quando ciência, técnica e informação passam a influenciar "os processos de remodelação do território essenciais às produções hegemônicas, que necessitam deste meio geográfico para sua realização", e onde vê-se que o campo "acolhe o capital novo e difunde-o rapidamente", num movimento de descentralização que, segundo o autor, "atinge muitas zonas e pontos longínquos do território nacional, deste modo envolvidos pelo nexo da modernização capitalista"(SANTOS, [1993]2005, p.38-47).

A dispersão urbana e o grande distanciamento entre núcleos urbanos ocupados são caracterizados, ainda, como fenômenos contemporâneos, pós-industrialização, consequentes de forças diversas, dentre elas as do mercado imobiliário sedento por novas (e mais baratas) áreas de ocupação, aliado ao recrudescimento da violência urbana, que leva as classes médias e altas a procurar uma segregação planejada (CALDEIRA, 2000; (LIMONAD, 2007); SPÓSITO, 2007).

Nestor Goulart sintetiza algumas das principais características da dispersão urbana: (1) descentralização da população, do emprego e dos serviços; (2) produção de "novas periferias"; (3) extensão da área urbanizada por vasto território, separadas fisicamente, mas fortemente interdependentes, formando um sistema urbano único; (4) desenvolvimento de novos modos de vida, viabilizados pela maior mobilidade (especialmente a individual), "organizando seu cotidiano em escala metropolitana e inter-metropolitana, envolvendo diversos municípios"; (5) novas formas de organização urbanística: condomínios e loteamentos fechados, empreendimentos de usos múltiplos isolados, shoppings centers - alteração das relações público - privado (REIS FILHO, 2006). Ainda segundo Reis, tudo isso estaria marcado pela

(...) adoção de novas modalidades de gestão dos espaços urbanos, com formas condominiais diversificadas, como nos loteamentos fechados, nos condomínios horizontais para residências ou fábricas e nos projetos de desenvolvimento urbano de maior porte, como em Alphaville ou Riviera de São Lourenço; (...) novas formas de organização do mercado imobiliário, com o surgimento de empreendimentos múltiplos, que reúnem residências, comércio, lazer, ensino, indústrias e escritórios

(REIS, 2006, p.12). 
Dentre todas as formas de organização espacial características da dispersão urbana acima identificadas, o condomínio horizontal e os loteamentos fechados são as mais conhecidas (e questionadas) deste processo no Brasil. A antropóloga Teresa Caldeira, autora de Cidade de Muros: Crime, segregação e cidadania em São Paulo, trabalho consolidado como uma importante referência para os estudos urbanísticos no Brasil, enumera as principais características da categoria de urbanização que ela denomina de "enclaves fortificados", e inclui shopping centers, conjuntos de escritórios, condomínios fechados verticais (de edifícios), mas também os condomínios horizontais (CALDEIRA, 2000, pp. 258-259). As características enunciadas pela autora sintetizam bem os principais argumentos contra os condomínios fechados, que, segundo ela,

\begin{abstract}
São de propriedade privada para uso coletivo e enfatizam o valor do que é privado e restrito ao mesmo tempo em que desvalorizam o que é público e aberto na cidade. São fisicamente demarcados e isolados por muros, grades, espaços vazios e detalhes arquitetônicos. São voltados para o interior e não em direção à rua, cuja vida pública rejeitam explicitamente. São controlados por guardas armados e sistemas de segurança, que impõe as regras de inclusão e exclusão. São flexíveis: devido ao seu tamanho, às novas tecnologias de comunicação, organização do trabalho e aos sistemas de segurança, eles são espaços autônomos, independentes do seu entorno, que podem ser situados praticamente em qualquer lugar. Em outras palavras, em contraste com formas anteriores de empreendimentos comerciais e residenciais, eles pertencem não aos seus arredores imediatos, mas a redes invisíveis (CENZATTI \& CRAWFORD, 1998). Em consequência, embora tendam a ser espaços para as classes altas, podem ser situados em áreas rurais ou na periferia, ao lado de favelas ou casas autoconstruídas. Finalmente, os enclaves tendem a ser ambientes socialmente homogêneos. Aqueles que escolhem habitar esses espaços valorizam viver entre pessoas seletas (ou seja, do mesmo grupo social) e longe das interações indesejadas, movimento, heterogeneidade, perigo e imprevisibilidade das ruas
\end{abstract}

(CALDEIRA, 2000, pp. 258-259)

A difusão dos condomínios fechados horizontais extrapolou as áreas metropolitanas e cidades de grande porte, tendo se espalhado como alternativa habitacional por grande parte das cidades brasileiras. Por esta razão, os condomínios e loteamentos fechados têm sido foco de inúmeros estudos, particularmente após os anos 1990, cujas críticas permanecem significativas até hoje. No entanto, como nos alerta Reis, 
Com frequência, as mudanças são vistas apenas sob a perspectiva restrita dos condomínios horizontais e dos loteamentos fechados, alvo das críticas mais comuns, que terminam por ser repetitivas (REIS, 2006, p.58).

Os moradores destes núcleos habitacionais segregados utilizam diversas estratégias para garantir a homogeneidade social interna e a "segurança" de suas propriedades, restringindo o acesso e impedindo a circulação aberta inerente às cidades desde a queda das muralhas medievais no século XVIII: muros, grades, guaritas, vigias, câmeras de segurança, protocolos de identificação de visitantes e empregados. Esforços que reconstituem, como metáfora, as antigas muralhas em uma versão tecnologicamente atualizada, mas que perpetuam as mesmas premissas daquelas, ou seja, mantém os "inimigos" e os "indesejados" do lado de fora da "cidade".

Considerando a importante ponderação de Reis sobre a crítica aos condomínios fechados, é essencial que um trabalho sobre a dispersão no século XXI considere as suas formas variadas e complexas, para além deles. Dentro desta perspectiva, renova-se o interesse em Alphaville como objeto de estudo, pois, apesar de alguns dos primeiros condomínios residenciais horizontais do Brasil terem sido lá construídos ${ }^{2}$, a partir de 1976, o empreendimento Alphaville-Barueri, como é conhecido, não se resume aos condomínios residenciais, tendo incorporado, desde o início e como elemento principal de seu projeto urbanístico, áreas destinadas a indústrias não-poluentes, comércio e serviços, constituindo um importante exemplo das formas complexas de organização espacial da dispersão urbana no Brasil.

Há farta bibliografia crítica à dispersão, particularmente após os anos 1990. Este período é caracterizado por Robert Bruegmann como uma "campanha contra a dispersão", em seu interessante (e raro) estudo sobre dispersão, suas limitações e vantagens intitulado Urban Sprawl: a Condensed History (2011). Bruegmann sintetiza os principais argumentos desta crítica: custos econômicos; custos ambientais pelo aumento do consumo de combustíveis e pela diminuição das terras agricultáveis e florestadas; problemas sociais relacionados à diminuição da urbanidade; a "ofensiva" contra o automóvel; a necessidade de se limitar o crescimento urbano; além de objeções estéticas e simbólicas.

Frente a este cenário, um outro grupo de pesquisadores ${ }^{3}$ passou a argumentar em prol de estratégias de contenção da dispersão urbana, reunidas em torno da ideia de cidade compacta, que para estes autores pode ser definida como um conjunto de

2 O primeiro condomínio residencial horizontal do Brasil foi o Bourganville, construído em Ribeirão Preto, SP (CALIL JUNIOR, FELDMAN, 2003).

3 Destacamos os trabalhos de Richard Rogers, Rod Burgess, Mike Jenks, na Inglaterra; Peter Newman e Jeffrey Kenworthy, na Austrália; Jan Gehl, na Dinamarca; Salvador Rueda, na Espanha; Marta Romero e Frederico Holanda no Brasil. 
estratégias

(...) para aumentar a área construída e as densidades residenciais; intensificar as atividades econômicas, sociais e culturais urbanas e manipular o tamanho, a forma e a estrutura da cidade e de sistemas de assentamentos, perseguindo os benefícios da sustentabilidade ambiental, social e global derivados da concentração das funções urbanas

(BURGESS, 2000, pp. 9-10).

Este conceito foi absorvido por parte do meio acadêmico e do meio técnico ligados ao Urbanismo como sendo a melhor resposta de ocupação do espaço frente a grandes questões da vida urbana relacionadas à degradação ambiental, ao consumo de combustíveis e emissão de gases poluentes, à mobilidade urbana, à exclusão sócio-espacial, e à decadência do espaço público.

Este debate sobre a cidade nos coloca diante de um importante paradoxo urbanístico do século XXI: estamos entre a dispersão e a compactação. Não que estas interpretações sobre a forma urbana sejam capazes de esgotar a complexidade da realização material da cidade. Nenhuma cidade é completamente compacta ou dispersa, e buscar classificá-las numa possível matriz única e determinada de níveis de coesão/dispersão não é o interesse desta pesquisa ${ }^{4}$. O que parece ocorrer, de fato, é uma sobreposição de processos de dispersão e compactação, cuja predominância varia em momentos históricos e geográficos distintos, como afirma Milton Santos enquanto discute "a dissolução da metrópole" (SANTOS, [1986]), 2005 e como defende Bernardo Secchi, que identifica um "paralelismo histórico" entre os dois processos (SECCHI, 2009).

Para ambos autores, as raízes desta contraposição entre compacidade e dispersão não são recentes, pois estão ligadas à própria história da urbanização e do urbanismo como ciência social. Milton Santos argumenta que:

O movimento de concentração-dispersão, próprio da dinâmica territorial em todos os tempos, ganha, todavia, expressões particulares seguindo os períodos históricos. Pode-se dizer, no caso do Brasil, que ao longo da sua história territorial, as tendências concentradoras atingiram número maior de

$4 \quad$ Sobre índices de dispersão, ver os trabalhos de Alain Bertaud e Stephen Malpezzi: The Spatial Distribution of Population in 48 World Cities: Implications for Economies in Transition. Disponivel em: <http://alainbertaud.com/ wp-content/uploads/2013/06/Spatia_-Distribution_of_Pop_-50_-Cities.pdf>. Acessado em Fevereiro de 2015; e de Rômulo Ribeiro e Frederico de Holanda: Proposta para Análise do Índice de Dispersão Urbana. Cadernos Metrópole, n.15, São Paulo: PUC-SP, $1^{\circ}$ semestre de 2006, p.49-70. 
variáveis, presentes somente em pouco pontos do espaço. Recentemente, as tendências à dispersão começam a se impor e atingem parcela cada vez mais importante de fatores, distribuídos em áreas mais vastas e lugares mais numerosos

(SANTOS, 2005, p. 100).

Seguindo uma linha interpretativa análoga àquela de Santos, Bernardo Secchi afirma que, para as cidades europeias, é possível identificar uma sequência de urbanização, primeiramente construída sobre a experiência da concentração progressiva, seguida pela fragmentação e dispersão do urbano em "territórios de dimensões inimagináveis", reconhecendo o ponto de inflexão entre uma e outra nos anos 1960 e 1970, para em seguida afirmar que um "olhar mais atento" reconheceria que as duas sequências não são subsequentes, mas sim paralelas, antecedendo até mesmo o século $X X$, destacando, assim, a importância histórica destas duas tendências morfológicas na constituição do espaço urbano (SECCHI, 2009).

Este paralelismo entre compactação e dispersão encontra seu ápice no século $\mathrm{XX}$, que, para Secchi, está dominado por duas angústias que o refletem, oscilando entre o medo da hiperconcentração de pessoas nas mega cidades, e o pavor do desaparecimento da cidade, dissolvida por territórios cada vez mais amplos, extensos e fragmentados.

\begin{abstract}
(...) a perspectiva de um crescimento irrefreável da cidade e o temor se sua dissolução em formas de implantações dispersas das quais é difícil compreender a função e o sentido futuros; entre o pesadelo de uma metrópole que se torna uma megalópole, lugar da concentração das massas de população cada vez mais imponentes, que perde a própria medida, que se torna desmesurada, estranha à experiência individual e coletiva de seus habitantes, que não é mais possível conhecer e dominar em seus aspectos técnicos e funcionais, e o temor, por outro lado, da dissolução do próprio conceito de cidade, do desaparecimento deste lugar mágico sede de todas as inovações políticas, culturais e tecnológicas que marcaram profundamente a história europeia e ocidental, em territórios de delimitações incertas
\end{abstract}

(SECCHI, 2009, p. 32). 
confronto entre concentração e dispersão, é possível identificar que essas angústias paradoxais foram problematizadas pelo pensamento urbanístico muito antes de 1900 . $E$ mais, que estas angústias não se restringiram aos países europeus, sendo também identificadas em outros países ocidentais como Estados Unidos, Canadá, Austrália, e mesmo no Chile, Argentina, e no Brasil.

As interpretações de Santos e Secchi de que, mais que tendências de urbanização exclusivamente contemporâneas, "novas", compacidade e dispersão sempre estiveram presentes na organização das cidades indica um percurso narrativo historiográfico de grande interesse, considerando o cenário atual profícuo em leituras catastróficas sobre o futuro da cidade. Uma narrativa histórica que revele a dispersão na cidade ao longo do tempo pode auxiliar no enfrentamento e crítica das teorias que insistem que a dispersão contemporânea é um fenômeno completamente novo, e que fatalmente levaria ao fim da cidade.

A questão da morte da cidade está presente nas interpretações de autores que, ao tratarem a compactação e a dispersão do tecido urbano de maneira tão dramática e catastrófica, levaram a crer que a urbanização contemporânea teria características absolutamente ímpares e inéditas na história da cidade ocidental. Para eles, estaríamos vivenciando um momento de ruptura no processo de urbanização; a cidade estaria se esvaindo em territórios amorfos e mutantes, impossíveis de serem reconhecidos como parte de uma construção social e histórica representada pelo signo linguístico de cidade.

No texto O reino do Urbano e a Morte da Cidade, Françoise Choay pontua que as transformações recentes das cidades europeias foram tão profundas que existe um desencontro entre o espaço urbano tal como está, e a palavra cidade, que não mais o define, indagando:

Não chegou o momento de admitir, sem sentimentalismos, o desaparecimento da cidade tradicional e de perguntar-nos sobre o que a substituiu, isto é, sobre a natureza da urbanização e sobre a não cidade que parece ter se convertido no destino das sociedades ocidentais avançadas?

(CHOAY, 2004, p. 2).

Choay constrói seu argumento baseada em uma narrativa de temporalidade ampla, considerando projetos e/ou propostas urbanísticos desde as intervenções de 
Haussmann até aqueles que ela define como "sinais de desconstrução": a cidade linear de Arturo Soria y Mata e os projetos urbanos de Le Corbusier. Nossa interpretação tem um sentido diverso das conclusões de Choay, para a qual os prenúncios teóricos e projetuais de dispersão da cidade anunciavam seu fim. Certamente, esses indícios de dispersão estavam imbuídos de uma visão fortemente crítica à cidade industrial adensada e compactada. Porém, essas ideias não tiveram capacidade de definir ou determinar um caminho único para o urbanismo daquele momento em diante, muito menos foram aplicadas de forma literal. Elas apenas se incorporaram ao seu repertório como possibilidades propositivas, como parte de uma paleta de configurações que se ampliou conforme os urbanistas iam deparando-se com a crise da cidade industrial.

A questão da "superação" da cidade, tanto como léxico quanto como espacialidade, foi posta pelo arquiteto norte-americano Melvin Webber em 1968, o qual influenciou, diretamente, a interpretação de "morte da cidade" de Françoise Choay. Webber assinala que as inovações tecnológicas na comunicação e no transporte foram tão radicais no século $X X$ que expandiram a escala da sociedade urbana para relações "cada vez mais independentes da cidade", em um processo que reduziu a importância do lugar e do espaço físico (WEBBER, 1968, p. 471).

Para Webber,

Nossos layouts compactos de cidade espelham diretamente as tecnologias mais primitivas em uso no tempo em que foram construídos. De modo similar, o padrão locacional das cidades no continente refletem as tecnologias disponíveis no momento em que estes assentamentos cresceram. (...) Assim, a cola que uma vez uniu estes assentamentos está se dissolvendo agora, e os assentamentos estão se dispersando por terrenos cada vez mais amplos

(WEBBER, 1968, p. 473).

É fato que a ampliação das comunicações e a facilidade de mobilidade por meio de diferentes tecnologias, especialmente do automóvel, flexibilizaram profundamente a relação de distâncias e interdependência entre os lugares de trabalho, moradia, e consumo no século XX. No mesmo sentido, é fato que essa flexibilização foi ainda maior para as classes ricas, que posuem meios econômicos para acessar as novas tecnologias. Webber compreende essa relação de privilégios, afirmando que as revoluções na comunicação e nos transportes "permitiram que uma classe afluente vivesse em qualquer lugar - nos subúrbios, nos distritos rurais, nas montanhas, que 
seja - mantendo-se minuciosamente "urbanas", participando completamente da vida intelectual, profissional e econômica". Por sua vez, os mais pobres foram conservados à margem do processo, "tornando-se cada vez mais "rurais" no sentido de que eles não participam das questões da comunidade global" (WEBBER, 1968, p. 470).

Porém, o descolamento entre as atividades sociais e o espaço profetizado por Webber não se realizou completamente com as novas tecnologias de comunicação e transporte. Não apenas porque o acesso e a utilização de tecnologias se deram de forma desigual, mas também porque a promessa de fluidez e velocidade das mudanças não se concretizou. Ricos e pobres, moradores do subúrbio ou das periferias pobres, podem até ter condições diversas de escolha de localidades para morar, trabalhar e consumir, mas todos ainda dependem, em graus variados, da localização dos lugares na cidade. A relação locacional do homem com o espaço urbano não foi superada. $A$ cidade e o acesso a ela permanecem fundamentais na construção do espaço urbano até a atual década do século XXI.

Para Margareth Pereira (2008), alguns dos autores que defendem a "morte" da cidade desenvolveram seus estudos considerando espaços de tempo muito curtos, o que os impediu de reconhecer que processos de transformação e reestruturação social, econômica e territorial são recorrentes na história da cidade, ampliando, assim, a sensação de perplexidade diante dos eventos contemporâneos:

No caso, a perplexidade e a abstração podem ser observadas em diversos textos de arquitetos, sociólogos, geógrafos, urbanistas que, buscando sinalizar uma mudança nas formas de interação social e em suas territorializações visíveis, levaram à construção e generalização de novas expressões adjetivadas como a "cidade contemporânea" (1988) e a "cidade genérica" (1994), de Koolhaas, e as "cidades globais" (1991), de S.Sassen, entre tantas outras [...]. Quanto mais especializadas nas análises conjunturais e distanciadas do trato com processos históricos e com os atores sociais observados de modo mais próximo, as áreas de saber reagiram com maior estranhamento e perplexidade a certos processos como as "macro regulações econômicas e de mercados", os "impactos tecnológicos"ou as "reconstruções da imagem das cidades" desenvolvendo discursos generalizantes pautados na maior parte dos casos em observação de aspectos econômicos e materiais mas, sobretudo, visuais das cidades, observados em temporalidades curtíssimas

(PEREIRA, 2008, p. 7). 
Parece-nos que, mais do que uma ruptura que desconstrói a cidade, a urbanização, desde a segunda metade do século XX, impõe uma (re)conceituação do que é cidade; uma releitura das diversas formas de ocupação e configuração do território urbano que incorpore, integre e abarque as intensas transformações que os últimos dois séculos forjaram no espaço. A tão defendida impressão de diluição e "morte" da cidade advém de leituras estreitas, que desconsideram as relações de apropriação e reapropriação realizadas, cotidianamente, pelos homens que vivem nos mais diversos lugares urbanizados. Se a cidade compacta dinamiza aglomerações mais numerosas de pessoas (HOLANDA, 2010a; 2010b; GEHL, 2013), não há como determinar a qualidade das interações sociais decorrentes, nem como afirmar que espaços menos densos implicam apropriações socioespaciais de menor significância (SABOIA, 2011; SABOIA; PALAZZO, 2012). Mesmo nos espaços mais difusos, menos densos, menos constituídos de características tradicionalmente compreendidas como "urbanas", os homens realizam suas vidas, insistentemente, dia a dia. Circulam, trabalham, encontram-se, estudam, consomem, produzem. A urbanização dispersa não matou a cidade. Foi a cidade que se transformou, incluindo outros modos e formas de viver, os quais não mais se restringem aos centros consolidados, aos quarteirões e esquinas, à aglomeração densa da cidade do século XIX. Se insistirmos em ver a cidade apenas nas imagens pregnantes da era pré-dispersão, perderemos a capacidade de encontrar a cidade atual, que abarca a cidade tradicional e muitas outras formas urbanas.

Como afirmou Milton Santos, ainda nos anos 1990, "Hoje, nas áreas mais desenvolvidas, todos os dados da regulação agrícola se fazem no urbano, novidade que, em muito, muda a significação, neste período, da urbanização brasileira" (SANTOS, [1986] 2005, p. 61).

Esta concepção se coaduna com a teoria de "urbanização total" desenvolvida por Henri Lefebvre em Revolução Urbana, de 1970. Para Lefebvre, a sociedade do século $X X$ tenderia à urbanização completa, que seria um domínio absoluto do campo e da natureza pela cidade,

Não é menos certo que a produção agrícola se converte num setor da produção industrial, subordinada aos seus imperativos, submetida às suas exigências. Crescimento econômico, industrialização, tornados ao mesmo tempo causas e razões supremas, estendem suas consequências ao conjunto dos territórios, regiões, nações, continentes. Resultado: o agrupamento tradicional próprio à vida camponesa, a saber, a aldeia, transforma-se; unidades mais vastas o absorvem ou o recobrem; ele se integra à indústria e ao consumo de produtos dessa indústria. A concentração da população acompanha a dos meios de produção. O tecido urbano prolifera, estende-se, corrói os 
resíduos da vida agrária

(LEFEBVRE, [1970] 1999, p.15).

E completa afirmando que é,

\begin{abstract}
Estranho e admirável movimento que renova o pensamento dialético: a não-cidade e a antcidade vão conquistar a cidade, penetrá-la, fazê-la explodir, e com isso estendê-la desmesuradamente, levando à urbanização da sociedade, ao tecido urbano recobrindo as remanescências da cidade anterior à indústria
\end{abstract}

(LEFEBVRE, [1970] 1999, p.23).

Conquanto reveladora e aberta, a teoria da urbanização total não é necessariamente incompatível com a permanência de uma ideia de cidade, ainda que esta ideia tenha, certamente, se alterado ao longo do tempo. Se a cidade possui uma relação heterotópica com o campo, como afirma Lefebvre (LEFEBVRE, [1970] 1999, p. 19 e 21), é completamente contraditório afirmar a "preferência" pelos termos "fenômeno urbano" e "o urbano" como substitutivos mais precisos à palavra "cidade". Como o próprio Lefebvre afirma no mesmo texto:

\footnotetext{
Estas palavras, "o tecido urbano", não designam, de maneira restrita, o domínio edificado nas cidades, mas o conjunto de manifestações do predomínio da cidade sobre o campo [grifos nossos](LEFEBVRE, [1970] 1999, p. 15).
}

Ora, se a cidade "explode" lançando seus "fragmentos" por sobre o território, espalhando-se não apenas fisicamente, mas fundamentalmente, em termos de modo de vida e de produção, ela não permanece a mesma; ela se expande e abarca, engloba, a partir da "inflexão do agrário para o urbano", outras modalidades de urbanização. 
E o que não existia como parte do tecido urbano, passa a ser parte da cidade. Fato espacial e social cuja denominação, alterada para outra, de "cidade" para "o urbano", tem sérias implicações para o campo do urbanismo. Primeiro, porque, admitindo-se que a cidade é uma entidade delimitada, cuja definição e determinação são materialmente possíveis, perde-se a capacidade de compreendê-la na sua complexidade, nas suas mais diversas expressões espaciais, o que nos parece contradizer a própria teoria da urbanização total. Segundo, porque se existe a cidade, essa pretensa entidade de forma definível e discernível, seu contraponto seria uma não-cidade, ou a negação dela. O conceito de não-cidade é danoso ao pensamento urbanístico, porque impõe uma contraposição que não existe - tudo é urbano, tudo é cidade na teoria da urbanização total - e solidifica uma ideia de que a cidade encarna o bem, e seus fragmentos espalhados, consequência de explosão, são inferiores, menos importantes, menos dignos de projeto, de planejamento e de reconhecimento. E como o próprio Lefebvre coloca,

Nessa acepção, uma segunda residência, uma rodovia, um supermercado em pleno campo, fazem parte do tecido urbano. Mais ou menos denso, mais ou menos espesso e ativo, ele poupa somente regiões estagnadas ou arruinadas, devotadas "à natureza”. (LEFEBVRE, [1970] 1999, p. 15).

Portanto, corroboramos uma outra linha de interpretação. Pereira (2008), por exemplo, argumenta que um olhar atento à história do processo de urbanização pode oferecer uma reação crítica à interpretação de que o momento atual é único e novo, completamente distinto e diverso na história da cidade:

\footnotetext{
A leitura dos compêndios de "história das cidades" ou de certos textos da "história das ciências sociais e humanas" nos permitem constatar o quanto são recorrentes os processos de mudança de escala, ritmo ou duração nas interações das cidades, bem como os processos de regulação nas tecnologias de comunicação e informação, de "ajustes" macroeconômicos ou de investimento nas reformas da imagem das cidades (PEREIRA, 2008, p.8, grifos nosso).
} 
Seguindo Margareth Pereira e a ideia de paralelismo entre compactação e dispersão elaborada por Secchi (2006; 2009), defendemos que a dispersão urbana do século XXI não configura um processo completamente novo na história da cidade e do urbanismo e que, por essa razão, não é despojada de relações com o pensamento urbanístico pregresso, tendo sido problematizada muito antes de 1900.

Esta constatação permite-nos construir uma argumentação que segue em um sentido diverso daquele proposto por alguns importantes teóricos do Urbanismo, como Nestor Goulart Reis, que classifica a dispersão urbana como uma "mudança de estado"(REIS, 2006, p.19), ou Françoise Choay, que argumenta que a cidade tradicional desapareceu (CHOAY, [1994] 2004). Defendemos que a dispersão não determina o fim da cidade, pois esta não se trata de uma ruptura, mas de uma transformação para uma constituição espacial muito mais complexa e heterogênea morfologicamente e sócio-culturalmente, que não se resume apenas à dualidade entre espaços compactos ou dispersos, mas que forma uma gama quase infinita de composições que ora tendem mais à diluição, ora mais ao adensamento.

Entendemos, ainda, que o debate entre dispersão e coesão também não constitui uma novidade na história da cidade e do urbanismo, e que a dispersão, hoje demonizada, foi proposta (e por diversas vezes, realizada) por muitos pensadores da cidade como uma solução de urbanização frente à hiper-concentração, especialmente na cidade industrial a partir da segunda metade do século XIX. Estas propostas de dispersão fazem parte de um significativo arcabouço projetual e conceitual do urbanismo que vem sendo gradualmente abandonado, e serão problematizadas para respaldar a interpretação que estamos propondo sobre as formas de urbanização dispersa do século XXI.

Muitas das propostas urbanísticas desenvolvidas a partir da segunda metade do século XIX questionaram e repensaram a cidade compacta a partir de diferentes níveis de ruptura. Conquanto as intervenções de Haussmann em Paris e Cerdà em Barcelona tenham deixado um influente legado de estratégias urbanísticas para viabilizar a adaptação de cidades "tradicionais" às transformações tecnológicas, econômicas, demográficas do século XIX (e XX) e, conjuntamente, tenham funcionado como reinterpretação do repertório morfológico de coesão para a expansão da cidade, várias outras propostas ofereceram a dispersão como solução urbanística.

As questões de diluição do adensamento, articulação de tipologias habitacionais e incorporação de novas tecnologias de transporte como estruturadoras da organização espacial e da dinâmica do cotidiano formaram um sólido arcabouço de projeto e de planejamento urbano desde a constituição do urbanismo como campo disciplinar, o que, segundo Choay (2005) e Calabi (2012), ocorreu no século XIX. A partir daquele momento, a dispersão foi definitivamente incorporada ao repertório projetual 
da cidade, dentro das mais diversas intenções, tais como: descompactação, como a Ciudad Lineal, do madrilenho Arturo Soria y Mata em 1886 (SORIA Y MATA, 1968; COLLINS, 1968); cooperativismo, como a cidade-jardim de Ebenezer Howard de 1889 (HOWARD, 1996); possibilidade de liberdade absoluta e expressão de democratização equitativa, como a Broadacre City, de Frank Lloyd Wright de 1930 (WRIGHT, 2008; FISHMAN, 1982); igualitarismo radical, como as propostas dos desurbanistas socialistas nas décadas de 1920 e 1930 (KOPP, 1974; QUILICI, 1978); hipercompactação dispersa, como a proposta por Le Corbusier nos planos de Une Ville Contemporaine pour 3 Millions d'Habitants, de 1922, do Plan Voisin, de 1925, e da Ville Radieuse, de 1930 (FISHMAN, 1982).

\section{CONCLUSÃO}

Esta negação da dispersão como parte legítima, historicamente construída e provavelmente inevitável da cidade tem tolhido o pensamento urbanístico crítico de hoje, homogeneizando e restringindo o projeto urbano e a própria vivência da cidade a uma única experiência possível e desejável, questões que a esse trabalho interessa problematizar, como parte de outros publicações realizadas nesse mesmo sentido. Dentro deste cenário, nos parece extremamente oportuno e valioso discutir os modos de dispersão urbana atuais frente à historiografia dos princípios urbanísticos que conformaram importantes propostas da dispersão desde o século XIX até o século $X X$. Este movimento pode abrir espaço para outros caminhos interpretativos sobre a dispersão, necessariamente reconhecendo distorções e descaminhos entre projeto e realidade, entre concepções intelectuais e como estas foram apropriadas pelo capital, pelo mercado imobiliário e pela sociedade, mas buscando apontar pressupostos urbanísticos que podem ser ainda válidos para a cidade do século XXI.

\section{REFERÊNCIAS}

ASCHER, F. Os novos princípios do urbanismo. São Paulo: Romano Guerra, 2010.

BRUEGMANN, R. La dispersión urbana: una historia condensada. Madrid: Consejería de Medio Ambiente y Ordenación del Territorio, 2011. 
CALABI, D. História do Urbanismo Europeu. São Paulo: Perspectiva, 2012.

CALDEIRA, T. P. R. Cidade de muros: crime, segregação e cidadania em São Paulo. São Paulo: EDUSP; Editora 34, 2000.

CALIL JÚNIOR, Ozório; FELDMAN, Sarah. O centro de Ribeirão Preto: os processos de expansão e setorização. 2003. Universidade de São Paulo, São Carlos, 2003.

CENZATTI, M., CRAWFORD, M. On public spaces, quasi-public spaces, and public quasi-spaces. In: Architecture and the (New) Public Sphere, Modulus 24, 1998: 14-21.

CHOAY, F. El Reino de lo Urbano y la Muerte de Ciudad. In: RAMOS, Á. M. (Ed.). Lo Urbano en 20 autores contemporáneos. Barcelona: ETSAB; UPC, 2004.

O urbanismo: utopias e realidades, uma antologia. São Paulo: Perspectiva, 2005.

COLLINS, G. R. Lo Sviluppo della Pianificazione Lineare. In: SORIA Y MATA, A. La Città Lineare. Milão: Alberto Mondadori, 1968.p.13-85.

ECHAVARRI, J. P.; DAUDÉN, F. J. L.; SCHETTINO, M. P. La ciudad paseable: recomendaciones para la consideración de los peatones en el planeamiento, el diseño urbano y la arquitectura. Madrid: CEDEX, 2009.

FERNANDES, A. Decifra-me ou te Devoro: Urbanismo Corporativo, Cidade-fragmento e Dilemas da Prática do Urbanismo no Brasil. In: PAVIANI, A.; GONZALES, S. F. N.; FRANCISCONI, J. G. (Org.).Planejamento e Urbanismo na atualidade brasileira. Brasília: Livre Expressão, 2013.

FISHMAN, R. Urban utopias in the twentieth century: Ebenezer Howard, Frank Lloyd Wright, and Le Corbusier. Cambridge, Mass: MIT Press, 1982.

GEHL, J. Life between buildings using public space. Washington: Island Press, 2011. . Cidades para pessoas. São Paulo: Perspectiva, 2013. .; GEMZØE, L. Novos espaços urbanos. Barcelona: Gustava Gili, 2002.

HOLANDA, F. R. B. Urbanidade: Arquitetônica e Social. In: ENCONTRO NACIONAL DA ANPARQ, 2010, Rio de Janeiro. Anais do I ENAnparq.Rio de Janeiro: Anparq, 2010a. Disponível em: <http://www.anparq.org.br/dvd-enanparq/simposios/163/163-307-1-SP. pdf>. Acesso em: 13 jul. 2015.

Brasília: cidade moderna, cidade eterna. Brasília: FAUnB, 2010b. 
HOWARD, E. Cidades-jardim do amanhã.São Paulo: Hucitec, 1996.

KOPP, A. Arquitectura y urbanismo soviéticos de los años veinte. Barcelona: Editorial Lumen, 1974.

LIMONAD, E. Urbanização dispersa mais uma forma de expressão urbana? Revista Formação, Presidente Prudente, n. 14, v. 1, p. 31-45, 2007. Disponível em: <http:// revista.fct.unesp.br/index.php/formacao/article/viewFile/705/728>. Acesso em: 13 jul. 2015.

MONCLÚS, J. La ciudad dispersa. In: (Ed.).La ciudad dispersa: suburbanización y nuevas periferias.Barcelona: CCBB, 1998.

MONTE-MÓR, R. L. Urbanização extensiva e a produção do espaço social contemporâneo. In: REIS FILHO, N. G.; TANAKA, M. M. S.; SPOSITO, M. E. B. (Org.).Brasil: estudos sobre dispersão urbana. São Paulo: FAU-USP, 2007. p. 241-251.

NEWMAN, P.; JENNINGS, I. Cities as sustainable ecosystems: principles and practices. Washington: Island Press, 2008.

NEWMAN, P.; KENWORTHY, J. R. Sustainability and cities: overcoming automobile dependence. Washington: Island Press, 1999.

PEREIRA, M. S. Dos conceitos de cidade ou pequeno manifesto em favor de objetos múltiplos, indecisos e fluídos. In: Seminário de História da Cidade e do Urbanismo, 2008, Recife.Anais do X SHCU.Recife: MDU/UFPE, 2008. Disponível em:<http:// unuhospedagem.com.br/revista/rbeur/index.php/shcu/article/view/1250/1224>. Acesso em: 15 jul. 2015.

QUILICI, V. Ciudad rusa y ciudad soviética: caracteres de la estructura histórica. Ideología y práctica de la transformación socialista. Barcelona: Gustavo Gili, 1978.

REIS FILHO, N. G. Notas sobre urbanização dispersa e novas formas de tecido urbano. São Paulo: Via das Artes, 2006.

RYKWERT, J. A ideia de cidade: a antropologia da forma urbana em Roma, Itália e no mundo antigo. São Paulo: Perspectiva, 2006.

SABOIA, L. Reconfiguring Brasilia's Modernist Landscape: the Openness of the Esplanade of Ministries. In: Annual Meeting of the Society for Architectural Historians, 64., 2011, New Orleans. The 64 th Annual Meeting of the Society for Architectural Historians. New Orleans: SAH, 2011. 
; PALAZZO, P. P. Capital in a Void: Modernist Myths of Brasilia. In: Biennial Conference of the International Association for the Study of Traditional Environments, 2012, Portland: IASTE, 2012.

SANTOS, M. A urbanização brasileira. São Paulo: EDUSP, 2005.

SANTOS JUNIOR, O. A.; MONTANDON, D. T (Org.). Os Planos Diretores Municipais Pós-Estatuto da Cidade: balanço crítico e perspectivas. Rio de Janeiro: Letra Capital; Observatório das Metrópoles; IPPUR/UFRJ, 2011.

SECCHI, B. Primeira lição de urbanismo. São Paulo: Perspectiva, 2006. . A cidade do século vinte. São Paulo: Perspectiva, 2009.

SORIA Y MATA, A. La Città Lineare. Milão: Alberto Mondadori, 1968.

SPOSITO, M. E. B. Novas formas de produção do espaço urbano no Estado de São Paulo. In: REIS FILHO, N. G.; TANAKA, M. M. S.; SPOSITO, M. E. B. (Org.). Brasil: estudos sobre dispersão urbana. São Paulo: FAU-USP, 2007. p. 7-28.

WEBBER, M. M. The Post-City Age. Daedalus, v. 97, n. 4, p. 1091-1110, 1968.

WIRTH, L. Urbanism as a Way of Life. The American Journal of Sociology, v. 44, p. 1-24, 1938.

WRIGHT, F. L. Modern architecture: being the Kahn lectures for 1930. Princeton: Princeton University Press, 2008.

Recebido em: 11/12/2019

Aprovado em: 16/10/2018

Publicado em: 20/12/2019 